\title{
'Thio-click' chemistry and microfluidics: A straightforward method towards macroporous and nonporous functional polymer beads
}

\author{
R. Arun Prasath, M. Talha Gokmen, Pieter Espeel, Filip E. Du Prez* \\ Polymer Chemistry Research Group, Department of Organic Chemistry, Ghent University, \\ Krijgslaan 281 S49000 Ghent, Belgium, e-mail: filip.duprez@ugent.be \\ *Corresponding author
}

Abstract: Thiol-ene and thiol-yne reactions (thio-click) are explored as efficient pathways towards rapid production of diverse monodisperse macroporous and nonporous functional beads. In a straightforward method, polymer beads containing amine, hydroxyl and carboxyl groups have been prepared by reacting a tetrafunctional thiol with a range of mono and/or multifunctional -enes/-ynes containing the desired functional groups. The 'thio-click' reaction has been performed in a simple home-made microfluidic device utilizing thiol and ene/yne monomers at a 1:1 ratio of thiol to $\pi$-bond. The porous functional beads were prepared making use of a porogen in combination with a photoinitiator. The optical and scanning electron microscopy images demonstrated monodispersity of the beads with a spherical shape ranging in size from 210 to $600 \mu \mathrm{m}$. The beads were characterized in terms of glass transition temperature, surface area measurement and composition. The accessible amine and hydroxyl loading in the beads ranges between 0.2 to $0.7 \mathrm{mmol} / \mathrm{g}$, as determined by the Fmoc method. This work demonstrates the applicability of 'thio-click' reactions in microfluidics as a powerful tool for the rapid design of functional beads for diverse applications.

Keywords: Thiol-ene; Thiol-yne; Click Chemistry; Polymer Beads; Porous Beads; Functional Beads; Microfluidics; 


\section{Introduction}

Porous and gel-type (nonporous) polymer beads play an important role in various applications, i.e. solid supported catalysis, ${ }^{1}$ ion exchange, ${ }^{2}$ enzyme immobilization, ${ }^{3}$ solid phase extraction (SPE), ${ }^{4}$ high performance liquid chromatography (HPLC), ${ }^{5}$ gel permeation chromatography (GPC), ${ }^{6}$ scavenging, ${ }^{7}$ solid phase organic synthesis (SPOS) ${ }^{8}$ and solid phase peptide synthesis (SPPS). ${ }^{9}$ For solid phase synthesis and catalysis applications, beads with a diameter of 100-300 micrometers are preferred, whereas chromatographic applications require beads with only few micrometers in diameter. $5,6,10$ The monodispersity and the porosity are crucial factors for most of the applications mentioned above. On the other hand, beads bearing reactive functional groups are essential when aiming for chemical modification reactions such as in SPOS and SPPS. The functional groups in the beads are either introduced by the functionality of the monomers or via post-modification step(s). In general, beads with high rigidity and porosity, size monodispersity, and controllable amounts of reactive functional groups are needed for most of the above mentioned applications.

The invention of chemical synthesis on a solid support ${ }^{11}$ resulted in revolutions in both peptide research and organic synthesis. As a result, drug discovery became much easier than before. $^{12}$ The first resins used in SPPS were based on styrene(St)-divinylbenzene (DVB) ${ }^{11}$ and various other types of resins were introduced for SPPS thereafter. ${ }^{13,14}$ Gel type St-DVB based Merrifield resins are still much in use, together with the later developed hybrid TentaGels, ${ }^{15}$ which are composed of a rigid St-DVB core and a hydrophilic poly(ethylene glycol) shell. A typical loading for TentaGel resin is as low as $0.2 \mathrm{mmol} / \mathrm{g}$, whereas the loading of Merrifield resins can reach up to $1.5 \mathrm{mmol} / \mathrm{g}$. Although the latter swells only in hydrophobic solvents, TentaGel swells in a wide range of solvents ranging from aqueous to organic ones. For nonporous resins, swelling is indeed crucial for the reagents to access the 
inner reactive sites. On the contrary, swelling is not necessary for macroporous resins ${ }^{16,17}$ since their relatively large pores allow reagents and even non-solvents to penetrate and find the reactive sites.

Generally SPPS is performed in the $\mathrm{C} \rightarrow \mathrm{N}$ approach meaning that amino acids are attached to the resin from their carboxyl terminus with the amino terminus being protected. For the $\mathrm{C} \rightarrow \mathrm{N}$ approach, resins bearing $-\mathrm{OH}$ and $-\mathrm{NH}_{2}$ groups are the most popular ones. ${ }^{18}$ However, most of the time $-\mathrm{NH}_{2}$ groups are introduced on the beads by post-modification step $(s)^{19-22}$ because the basic amine carrying monomers such as aminomethyl styrene, aminoethyl acrylate and aminoethyl methacrylate are commercially unavailable due to their instability. Nevertheless, examples of amine containing monomer preparation and subsequent polymerization are reported in literature. ${ }^{23}$ Furthermore, the well-known high reactivity of primary amine groups towards acrylates via Michael addition ${ }^{24}$ limits this strategy. Consequently a novel direct preparation strategy for amino, carboxyl and hydroxyl bearing beads in a controlled fashion is desired.

Traditional bead preparation is conducted via heterogeneous polymerization techniques that are all based on immiscibility of two or more phases. Suspension, emulsion, miniemulsion, dispersion and precipitation polymerizations are all well known for their advantages and disadvantages. ${ }^{25}$ Both emulsion and mini-emulsion processes can produce nanometer-sized beads but lacks porosity ${ }^{26}$. On the contrary, suspension polymerization can produce porous ${ }^{27}$ micron sized beads, but the obtained beads are inherently polydisperse in their size ${ }^{28}$ and necessitate sieving afterwards. In the seeded version of suspension polymerization ${ }^{5}$, monodisperse nanometer-sized seed particles (prepared by emulsion polymerization) are swollen by monomer, crosslinker and porogen in a second suspension media and polymerized thereafter. With this advanced technique, beads with high porosity and monodisperse character are obtained in a two step process. Precipitation polymerisation appears to be the 
most advantageous method since one can obtain monodisperse, porous beads by using suitable solvent mixtures ${ }^{6}$ in a single batch. However, like in seeded suspension polymerization the obtained beads are in the range of $0.1-10$ micrometer, which is not suitable for solid phase synthesis and catalysis applications due to handling problems. Also, the incorporation of functional monomers can be problematic or impossible ${ }^{29}$, because of the delicate mechanism of growing polymer chain precipitation during the polymerization.

In recent years there has been a growing interest to produce particles based on microfluidics technology. ${ }^{30}$ This is an advanced version of suspension polymerization where droplet formation is precisely controlled by linear flow instead of chaotic agitation. In a micro channel, continuous linear flow of a carrier phase drags the discrete monomer phase as monodisperse droplets due to viscous forces and interfacial tension. ${ }^{31}$ Solidification of these monodisperse droplets (generally on-flight) results in beads with a very narrow size distribution. Microfluidic emulsification also enables researchers to use porogens in order to obtain porous beads. ${ }^{32-34}$ In general, microfluidic systems are very tolerant to changes in ingredients, so one can easily change monomer, crosslinker and porogen(s) to look for the best combination without difficulty for the bead production. The capability of a one step synthesis to obtain monodisperse, functional, porous and nonporous beads makes microfluidics a quite attractive technique among the heterogeneous polymerizations. Moreover, microfluidics seems to be the most suitable approach for particles with various shapes such as nano to micro bead-in-bead assemblies, ${ }^{35}$ microcapsules, ${ }^{36}$ non-spherical particles, ${ }^{37}$ Janus particles, ${ }^{38}$ metal doped polymer rods ${ }^{39}$, poly(HIPE) beads and rods ${ }^{40}$.

In this paper, we present a simple microfluidic approach to prepare both gel-type and macroporous amine, hydroxyl and carboxyl functionalized monodisperse beads via thiol-ene and thiol-yne polymerizations without any post-modification steps. Addition of thiols to carbon-carbon double bonds is a century-old chemistry, however recently a couple of 
research groups ${ }^{41-44}$ have shown that the reaction of a thiol with an unsaturated bond, referred to as 'thiol-ene' chemistry, has many of the features of 'click' chemistry.$^{45}$ Later, it has been shown that not only addition of thiols to alkenes (thiol-ene) but also to alkynes (thiol-yne; double addition) reaches high conversions in short times via photopolymerization. ${ }^{46,47}$

As a rapid photopolymerization is very attractive and efficient process, we decided to explore thiol-ene and thiol-yne approaches to create polymer beads using a simple microfluidic setup, which is composed of UV transparent tubing, needles and syringe pumps (Figure 1). ${ }^{48,49}$ Also the orthogonality of thiol-ene/yne reactions in the presence of various functional monomers will be demonstrated. The fact that there are many functional thiols, alkenes and alkynes readily available further explains our interest to apply thiol-ene/yne photopolymerizations for the one-step creation of functional beads. Finally, the addition of porogen(s) to the discrete phase enabled us to prepare macroporous beads. These novel beads may have different performance characteristics compared to the commercial resins that are based on vinyl polymerizations.

\section{Experimental section}

Materials: The monomers pentaerythritol tetrakis(3-mercaptopropionate) [ 97\%, tetra thiol, (TT)], diallyl phthalate (97\%, DAP), triallyl-135 triazine trione (98\%, TTT), 1,7-octadiyne (98\%, OY), mercaptoacetic acid (97\%, MA), allylamine (98\%, AA), pentaerythritol triallyl ether (70\%, PTE) and propargylamine (98\%, PA), the photoinitiator 2,2-dimethoxy-2- 


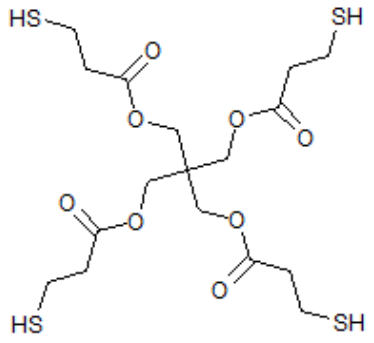

Pentaerythritol tetrakis(3-mercaptopropionate) (TT)

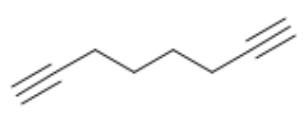

1,7-Octadiyne

(OY)

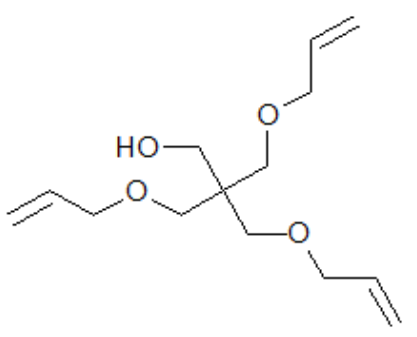

Pentaerythritol triallyl ether (PTE)<smiles>C=CCOC(=O)c1ccccc1C(=O)OCC=C</smiles>

Diallyl phthalate (DAP)<smiles>C=CCN</smiles>

Allyl amine

(AA)

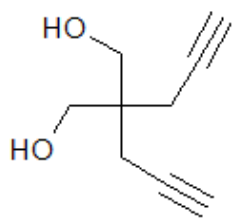

2,2-di(prop-2-ynyl)propane-1,3-diol (DPPD)<smiles>C=CCn1c(=O)n(CC=C)c(=O)n(CC=C)c1=O</smiles>

Triallyl-135 triazine trione

(TTT)<smiles>C#CCN</smiles>

Propargylamine

(PA)

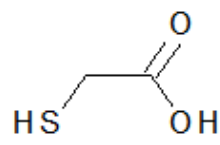

Mercaptoacetic acid (MA)

Figure 1: Structures and acronyms for tetrathiol, ene and yne compounds

phenylacetophenone (99\%, DMPA), the solvents acetonitrile (AN), tetrahydrofuran (THF), 1,4-dichlorobenzene (DCB), dibutyl phthalate (DBP), diethyl phthalate (DEP), dioctyl phthalate (DOP), o-xylene (Xy) and $n$-butyl acetate (BuAc), light mineral oil as carrier phase, the surfactant sodium dodecyl sulfate (95\%, SDS), and the reagents, $N, N^{\prime}-$ diisopropylcarbodiimide (99\%, DIC) N,N-diisopropylethylamine (99\%, DIPEA), 4(dimethylamino)pyridine (99\%, DMAP), 5,5"-Dithiobis(2-nitrobenzoic acid) [99\%, Ellman’s reagent], (benzotriazol-1-yloxy)- tripyrrolidinophosphonium hexafluorophosphate (98\%), piperidine (99\%) were used as received from Sigma-Aldrich. Fmoc-glycine was purchased from Novabiochem and used as such. 2,2-di(prop-2-ynyl)propane-1,3-diol (DPPD) and (2- 
\{Ethyl-[4-(4-nitro-phenylazo)-phenyl]-amino\}-ethoxy)-acetic

acid-4-nitro-phenyl

ester

(NF31) were synthesised in-house according to the reported literature. ${ }^{50,51}$ PVC $[1.6 \mathrm{~mm}$ inner diameter, (ID)] and Tygon tubes (0.8 mm ID) were purchased from Sigma-Aldrich and VWR international respectively. 30G and 32G disposable needles were purchased from Becton Dickinson. A metalight UV box operating with 12 lamps (Philips 9W, intensity was $\sim 2.5 \mathrm{~mW} / \mathrm{cm}^{2}, 320-400 \mathrm{~nm}$ ) was used. The surfactant ABIL EM-90 was kindly donated by Evonik Degussa. Solvents such as dimethylformamide, dimethyl sulfoxide, 1-methyl-2pyrrolidinone were of analytical grade from Sigma-Aldrich. Methanol, dichloromethane, acetone and diethyl ether were of technical grade and used as received from Fiers (Belgium). MilliRO grade water was used for all purposes. Chemical structures of the tetrathiol, -enes and -ynes used in this work are given in Figure 1.

Preparation and analysis: Beads were prepared using a home-made microfluidic setup as shown in Figure 2. Typically, the reagent phase consists of thiol and ene/yne monomers at a 1:1 ratio of thiol to $\pi$-bond, photoinitiator DMPA 2-5 mol\% to thiol and with or without 60 to $80( \pm 2) \mathrm{wt} \%$ of a porogen. For nonporous bead preparation, the continuous phase was light mineral oil containing 0.25 wt\% surfactant (ABIL EM-90). In the case of porous bead preparation, the continuous carrier phase was an aqueous SDS solution (3 wt\%). The continuous phase (oil or water) flows through the tubing (PVC or Tygon) and the reagent phase (dispersed phase) was injected into the continuous phase using a blunt bent needle (30G or 32G), which was inserted halfway the tubing (as shown in Figure 2). The continuous phase was pumped using a syringe pump with a syringe of $150 \mathrm{~mL}$ capacity and the reagent phase was pumped using a second syringe pump with a syringe of $1 \mathrm{~mL}$ capacity. The flow rates (varied independently) of the continuous and reagent phase were between 60 to $90 \mathrm{~mL} / \mathrm{h}$ and 0.1 to $0.3 \mathrm{~mL} / \mathrm{h}$ respectively. The length of the tubing was varied between 2 and 4 meters and formed in the shape of helices inside the UV chamber, which allowed the formed 
droplets to be continuously irradiated to UV light. After collection, the beads were further exposed to UV irradiation for approximately one hour in favour of quantitative 'click' reactions to occur in the beads. Beads collected from oil carrier phase were first washed with dichloromethane to remove the oil and ABIL, and subsequently with methanol, water, acetone and diethyl ether to remove any impurities from the beads. Beads collected from the aqueous carrier phase were first washed with water and subsequently with methanol, dichloromethane, acetone and diethyl ether. Finally beads were dried under high vacuum at $90^{\circ} \mathrm{C}$ overnight.

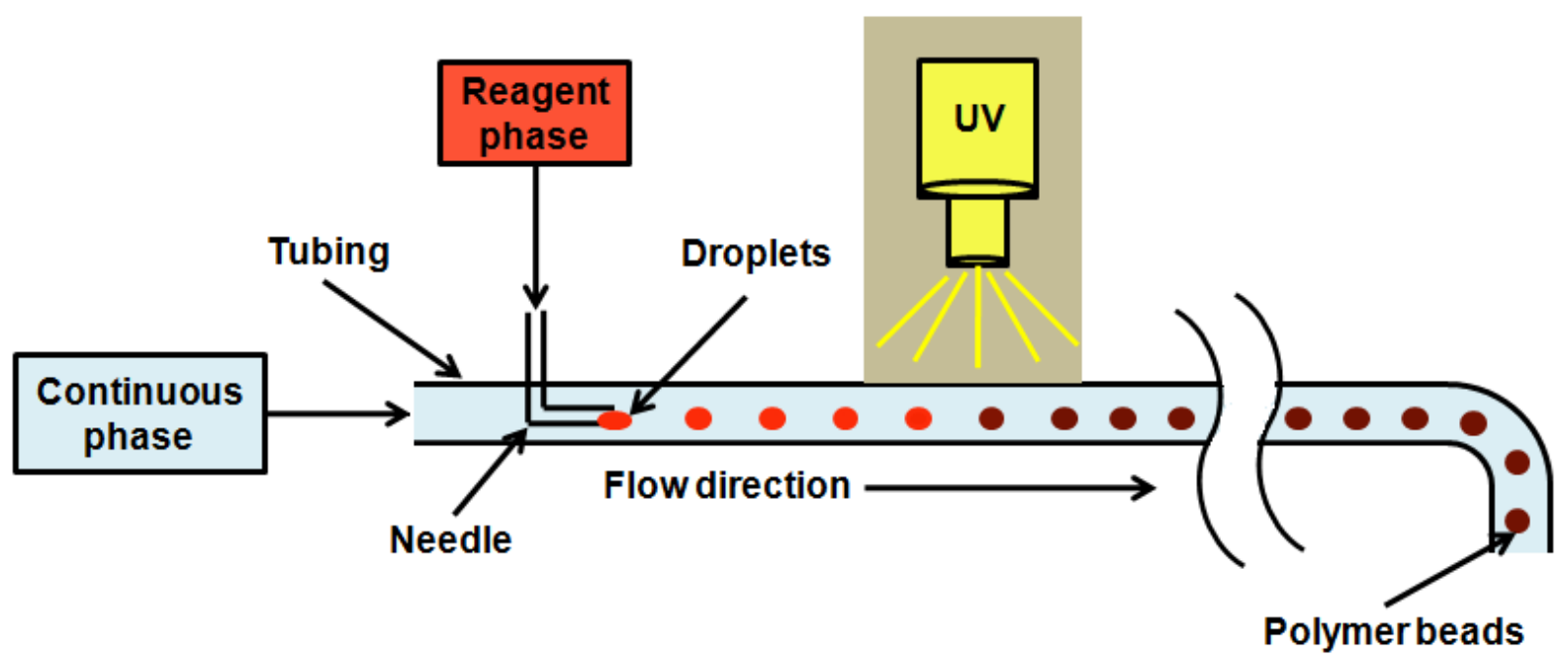

Figure 2: Schematic drawing of the microfluidic setup.

The size and morphology of the beads were analyzed by optical microscopy (OM, Nikon SMZ800 microscope) and scanning electron microscopy (SEM, Quanta 200FEG FEI). The glass transition temperature $\left(\mathrm{T}_{\mathrm{g}}\right)$ of the beads was measured by differential scanning calorimetry (DSC Perkin Elmer 7). Specific surface area values were determined by measuring the adsorption and desorption isotherms of nitrogen on a Belsorp-mini II apparatus with a bath temperature of $77 \mathrm{~K}$ and evaluated with Bel Master Software (BET method). Fourier transform infrared (FTIR) spectra and Raman spectra were collected on a Nicolet 
Impact $400 \mathrm{D}$ spectrometer and the Renishaw System-1000 Raman spectrometer respectively. Gravimetric analysis was carried out to determine the yield for the prepared nonporous and porous beads. For the $-\mathrm{NH}_{2}$ containing beads, amine loading was estimated via the Fmoc method. ${ }^{52}$ Similarly, hydroxyl loading in the porous and nonporous hydroxyl containing groups was estimated by the Fmoc method. In short, Fmoc-glycine was activated by reacting Fmoc-glycine ( $0.2 \mathrm{~mol}$, in dry dichloromethane) with DIC (0.2 mol) for $20 \mathrm{~min}$ at room temperature. The activated Fmoc reagent was added $(2$ eq to hydroxyl loading) to the beads (25-30 mg) followed by DMAP addition (0.2 eq to hydroxyl loading) in a $5 \mathrm{ml}$ vial. The vial was shaken on an orbital shaker for 2 hr and then washed with DMF, MeOH, DCM and DEE (3x each) followed by vacuum drying. Approximately $20 \mathrm{mg}$ of the beads was transferred in a round bottom flask. A solution of $20 \%$ piperidine/NMP $(15 \mathrm{~mL})$ was added to the flask and swirled occasionally. After $30 \mathrm{~min}$, the solution was transferred to an UV cuvette and the absorption of the adduct piperidine-dibenzofulvene at $300 \mathrm{~nm}$ was measured with the same 20\% piperidine/NMP solution as the blank solution. The hydroxyl loading was calculated using the Lambert's Beer Law. The beads were also subjected to a simple colorimetric test ${ }^{53}$ and Ellman's colorimetric test ${ }^{54}$ for qualitative detection and quantitative estimation of unreacted thiols.

\section{Results and Discussion}

Pentaerythritol tetrakis(3-mercaptopropionate) was selected as the tetrafunctional thiol monomer (TT), which is capable to form crosslinked networks with di/multifunctional -ene monomers or with mono/multifunctional -yne monomers. DAP, TTT, and OY were used as multifunctional -ene monomers and -yne monomer respectively. Functional monomers such as MA (thiol-carboxyl), PTE (ene-hydroxyl), DPPD (yne-hydroxyl), AA (ene-amine) and PA 
(yne-amine) were selected to obtain polymer beads bearing reactive functional groups. Although PA is a monofunctional -yne monomer, it is capable of undergoing a double consecutive reaction with two thiol groups to form a dithioether crosslinking point. ${ }^{46}$ The thiol-yne reaction proceeds by the addition of a thiyl radical to an -yne with the formation of a carbon centred radical, which subsequently abstracts a hydrogen from another thiol. The generated vinyl sulfide moiety is capable of undergoing a further reaction through addition of a second thiyl radical, similar to the thiol-ene reaction. Scheme 1 gives the possible stepgrowth network formed in the bead by typical thiol-ene and thiol-yne 'click' reactions. Apart from the 'thio-click' reactions, other possible side reactions such as disulfide formations (thiyl radicals), intramolecular reactions (cyclization) and homopolymerizations (carbon radicals) may also take place. More detailed information about the thiol-ene and thiol-yne photoinitiated reaction mechanisms can be found in literature. ${ }^{46,55}$
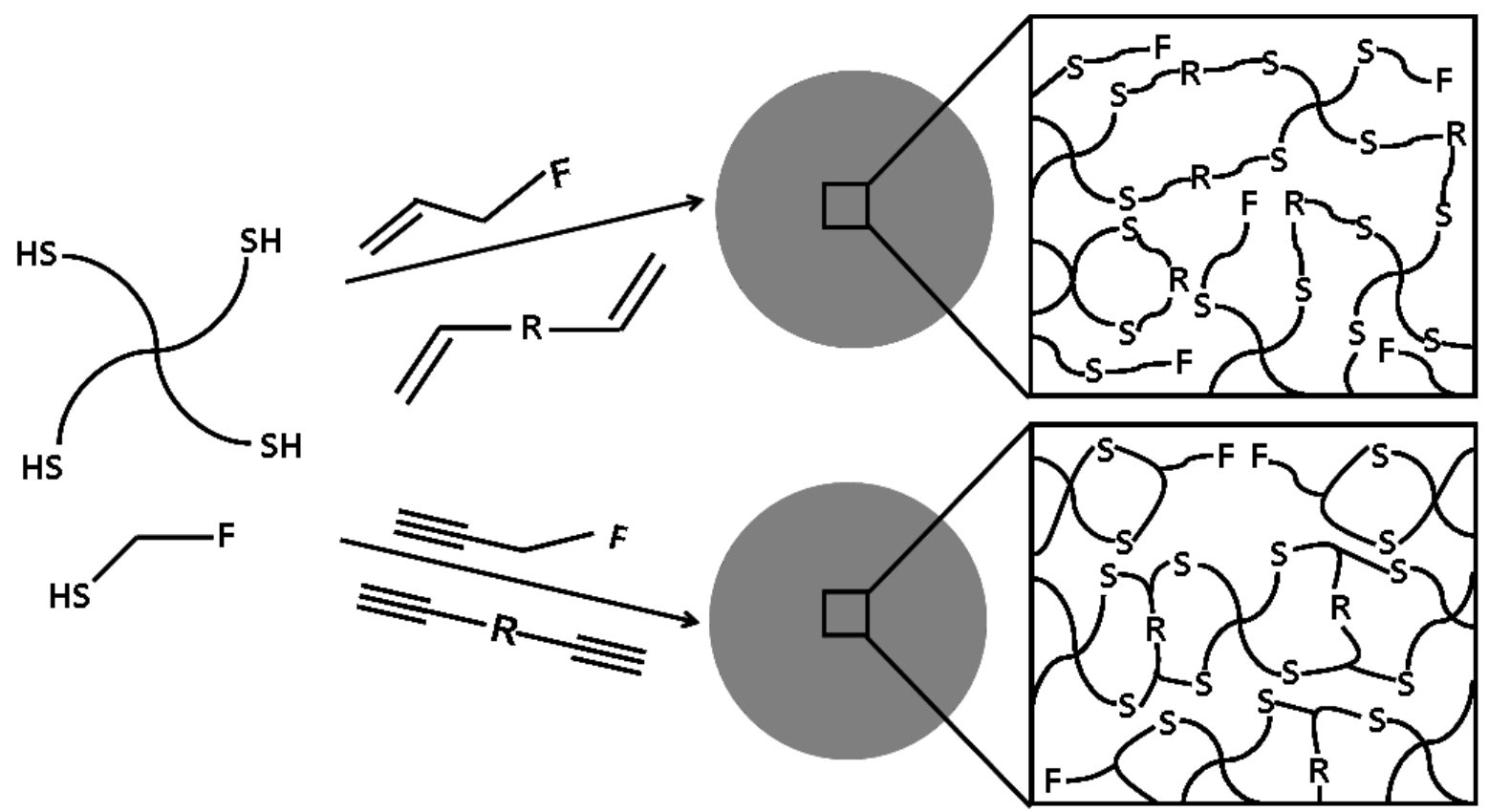

Scheme 1: Ideal representation of step-growth network formation in the bead by thiol-ene and thiol-yne 'thio-click' reactions $\left(\mathrm{F}=-\mathrm{NH}_{2},-\mathrm{OH}\right.$, or $\left.-\mathrm{COOH}\right)$.

In general, monodisperse droplets were generated by adjusting the flow rate of both the continuous and reagent phase in the microfluidic system. The generated droplets are 
separated with an approximate distance of about $5 \mathrm{~mm}$, thus avoiding the droplet coalescence inside the tubing. Also, the presence of a surfactant (ABIL in oil or SDS in water) facilitates the smooth motion of the droplets in the tubing and eliminates the possible problem of blockage. In addition, the surfactant provides stability to the droplets until they get photopolymerized in the UV chamber to form the final monodisperse beads. Typically, the time of the photopolymerization between the tetrafunctional thiol and various mono/multifunctional enes/ynes (at 1:1 ratio of thiol to $\pi$-bond) to form highly crosslinked beads was varied from 30 to 180s. It was reported for the thiol-yne addition reaction that the first step, leading to the formation of the vinyl sulfide, is slower than the reaction between the thiol and vinyl sulfide. ${ }^{46}$ In our hands, a very rapid reaction was observed for both the thiolene and the thiol-yne formulations under the applied conditions. Moreover, each droplet generated in the microfluidic system has roughly the same exposure to UV irradiation, which was favoured by the spin movement of the droplets downstream of the tubing, thus facilitating homogenous curing in the droplets.

\section{Nonporous beads}

The nonporous functional beads were prepared using the following 'thio-click' formulations in bulk: TT/(DAP+AA), TT/PTE and TT/PA (see Figure 1 for abbreviations). On the other hand, since DPPD is immiscible with TT, DMSO ( 25 wt\%) was used as a solvent to prepare the TT/DPPD formulation. Figure 3 shows representative optical and SEM images of the functional beads prepared in the absence of a porogen. The hexagonal close packing of the beads (Figure 3a) clearly illustrates their monodispersity. For the TT/PA formulation, 'satellite' beads are also observed along with larger monodisperse beads (Figure 3b). The average size varies between $285 \mu \mathrm{m}$ and $600 \mu \mathrm{m}$ for the various functional beads prepared (Table 1). The SEM images recorded for the amine and hydroxyl containing thiol-ene beads 


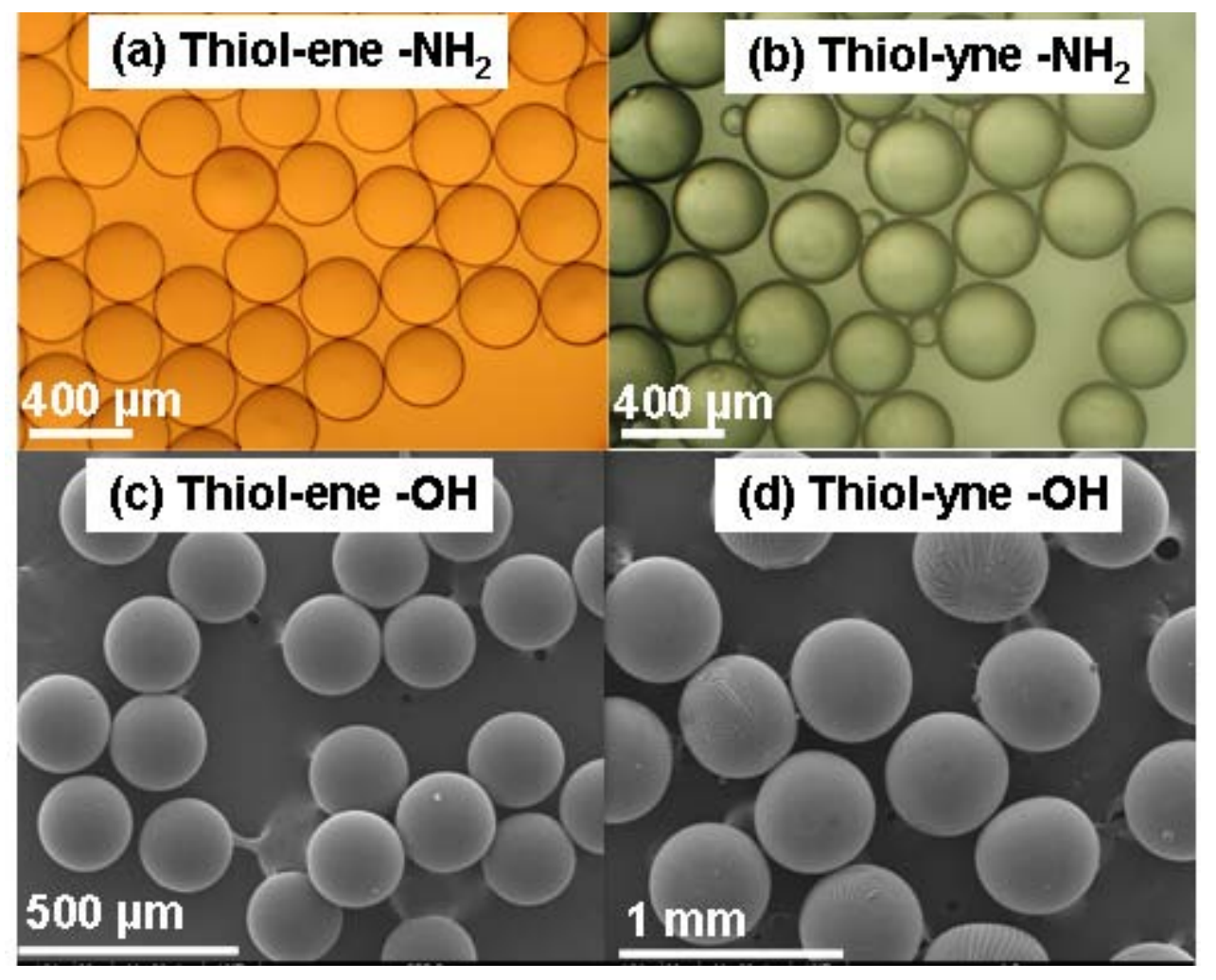

Figure 3: Representative optical (top) and SEM (bottom) images of the nonporous functional beads prepared from the formulation of (a) TT/(DAP+AA), (b) TT/PA, (c) TT/PTE and (d) TT/DPPD.

showed shrinkage of 20 and 26\% respectively as compared to the corresponding optical images. This shrinkage phenomenon can be attributed to the low stiffness of the crosslinked networks, which is supported by the low $\mathrm{T}_{\mathrm{g}}$ values, i.e. 0 and $3{ }^{\circ} \mathrm{C}$ for the amine and hydroxyl containing beads respectively (Table 1). In contrast, very little change in the dimensions was observed for the beads prepared from thiol-yne formulations, TT/PA and TT/DPPD. This is attributed to the higher stiffness in the crosslinked thiol-yne based beads as a result of the restricted rotation of dithioether linkages and their higher cross-link density compared to the beads prepared by thiol-ene chemistry. The $\mathrm{T}_{\mathrm{g}}$ values for the amine and hydroxyl containing thiol-yne beads are 33 and $45{ }^{\circ} \mathrm{C}$ respectively (Table 1). The yields for the nonporous beads are in the range of 70 to $82 \%$. 
Table 1: Properties of nonporous and macroporous beads

\begin{tabular}{|c|c|c|c|c|c|c|c|}
\hline $\begin{array}{l}\text { Bead Type } \\
\text { (+ functional group) }\end{array}$ & $\begin{array}{l}\text { Sample } \\
\text { Formulation }\end{array}$ & $\begin{array}{l}\text { Functional } \\
\text { monomer } \\
\text { ratio }\end{array}$ & $\begin{array}{l}\text { Size } \\
\text { by } \\
\text { OM } \\
(\mu \mathrm{m})\end{array}$ & $\begin{array}{l}\text { Size } \\
\text { by } \\
\text { SEM } \\
(\mu \mathrm{m})\end{array}$ & $\begin{array}{l}\mathrm{T}_{\mathrm{g}} \\
\left({ }^{\circ} \mathrm{C}\right)\end{array}$ & $\begin{array}{l}\text { Specific } \\
\text { Surface } \\
\text { Area- } \\
\left(\mathrm{m}^{2} / \mathrm{g}\right)\end{array}$ & $\begin{array}{l}\text { Yield } \\
\text { (\%) }\end{array}$ \\
\hline Nonporous amine * & $\mathrm{TT} /(\mathrm{DAP}+\mathrm{AA})$ & $\begin{array}{l}\text { DAP:AA at } \\
0.65: 0.35\end{array}$ & 325 & 260 & 0 & - & 77 \\
\hline Nonporous hydroxyl * & TT/PTE & - & 285 & 210 & 3 & - & 82 \\
\hline Nonporous amine $* *$ & TT/PA & - & 350 & 340 & 33 & - & 73 \\
\hline Nonporous hydroxyl ** & TT/DPPD & - & 600 & 580 & 45 & - & 70 \\
\hline Porous amine * & $\mathrm{TT} /(\mathrm{DAP}+\mathrm{AA})^{\mathrm{a}}$ & $\begin{array}{l}\text { DAP:AA } \\
\text { at } 0.65: 0.35\end{array}$ & 375 & 255 & 3 & 0 & - \\
\hline Porous amine * & $\mathrm{TT} /(\mathrm{DAP}+\mathrm{AA})^{\mathrm{b}}$ & $\begin{array}{l}\text { DAP:AA } \\
\text { at } 0.65: 0.35\end{array}$ & 355 & 280 & 7 & 0 & 62 \\
\hline Porous hydroxyl * & $\mathrm{TT} / \mathrm{PTE}^{\mathrm{b}}$ & - & 265 & 240 & 4 & 0.7 & 75 \\
\hline Porous carboxyl * & $(\mathrm{TT}+\mathrm{MA}) / \mathrm{TTT}^{\mathrm{b}}$ & $\begin{array}{l}\text { TT:MA } \\
\text { at } 0.75: 0.25\end{array}$ & 330 & 325 & 40 & 4.9 & 71 \\
\hline Porous amine** & $\mathrm{TT} /(\mathrm{OY}+\mathrm{PA})^{\mathrm{b}}$ & $\begin{array}{l}\mathrm{OY}: \mathrm{PA} \\
\text { at } 0.75: 0.25\end{array}$ & 280 & 240 & 38 & 35.6 & 66 \\
\hline Porous amine ${ }^{* *}$ & $\mathrm{TT} /(\mathrm{OY}+\mathrm{PA})^{\mathrm{c}}$ & $\begin{array}{l}\text { OY:PA } \\
\text { at } 0.75: 0.25\end{array}$ & 320 & 300 & 44 & 3.5 & - \\
\hline Porous amine ${ }^{* *}$ & $\mathrm{TT} /(\mathrm{OY}+\mathrm{PA})^{\mathrm{b} \neq}$ & $\begin{array}{l}\mathrm{OY}: \mathrm{PA} \\
\text { at } 0.25: 1\end{array}$ & 270 & 250 & 13 & 2.3 & - \\
\hline Porous hydroxyl ** & $\mathrm{TT} /(\mathrm{OY}+\mathrm{DPPD})^{\mathrm{b}}$ & $\begin{array}{l}\text { OY:DPPD } \\
\text { at } 0.75: 0.25\end{array}$ & 305 & 255 & 40 & 9.3 & - \\
\hline Porous hydroxyl ** & $\mathrm{TT} /(\mathrm{OY}+\mathrm{DPPD})^{\mathrm{d}}$ & $\begin{array}{l}\text { OY:DPPD } \\
\text { at } 0.75: 0.25\end{array}$ & 340 & 300 & 42 & 2.2 & - \\
\hline
\end{tabular}

*thiol-ene system; **thiol-yne system; ${ }^{\mathrm{a} D O P}$ as porogen; ${ }^{\mathrm{b}} \mathrm{BuAc}$ as porogen, ${ }^{\mathrm{C}} \mathrm{Xy}$ as porogen, ${ }^{\mathrm{d}} \mathrm{Xy}$ and BuAc as porogen (ratio of $\mathrm{Xy}$ to BAc is $4.5: 3.5),{ }^{\neq}$ratio of thiol to $\pi$-bond $1: 1.25$ 


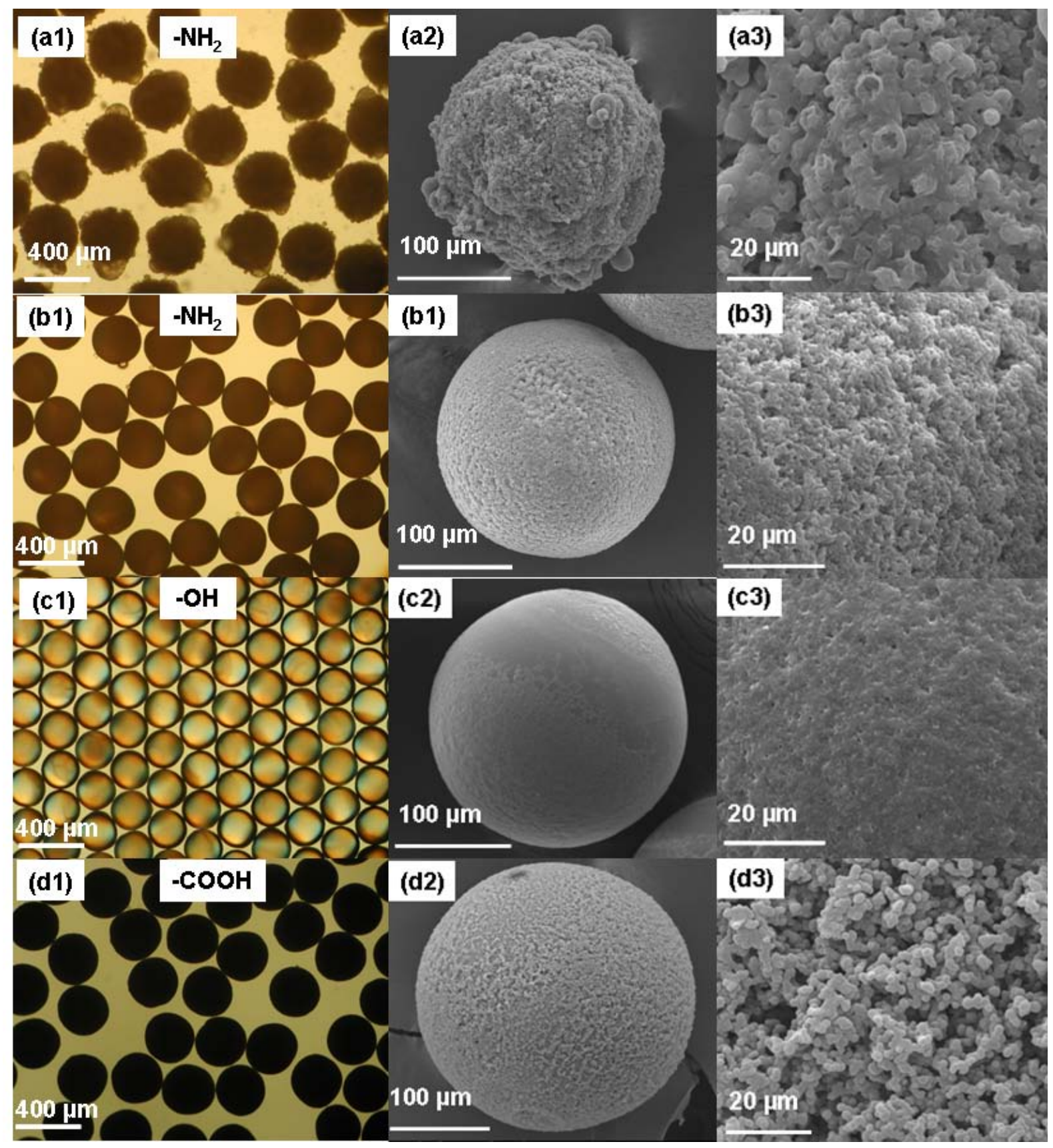

Figure 4: Representative optical (left) and SEM (middle and right) images of the porous functional beads prepared from the 'thiol-ene' formulation of (a) TT/(DAP+AA) (d) (TT+MA)/TTT .

${ }^{\mathrm{a}} \mathrm{DOP}$ as porogen; ${ }^{\mathrm{b}} \mathrm{BuAc}$ as Porogen. 


\section{Porous Beads}

The porous functional beads were prepared using the following formulations containing 60 to 80( \pm 2$)$ wt $\%$ of a porogen: TT/(DAP+AA), (TT+MA)/TTT, TT/PTE, TT/(OY+PA), and TT/(OY+DPPD). Among the range of porogens studied (DCB, DBP, DEP, DOP, o-xylene, n-butyl acetate, and mixtures of porogens), n-butyl acetate performed the best in most of the cases in terms of the formation of beads with a spherical shape and porosity. Figure 4 shows representative optical and SEM images of the porous functional beads prepared with the addition of a porogen to various thiol-ene formulations. The porous amine containing beads prepared in a first trial from the formulation $\mathrm{TT} /(\mathrm{DAP}+\mathrm{AA})$ containing $60 \mathrm{wt} \%$ of the porogen DOP, showed a distorted, non-spherical surface (Figure 4a). In contrast, welldefined spherical porous beads were prepared with the same formulation containing n-butyl acetate (60 wt\%) as the porogen (Figure 4b). Thus, the latter porogen was also used for the generation of hydroxyl (Figure 4c) and carboxyl (Figure 4d) containing beads. Porous thiolene beads with an average size between 330 to $375 \mu \mathrm{m}$ (Figure 4a1, $4 \mathrm{~b} 1$ and 4d1) were prepared using a 30G needle at a pumping rate of $0.2 \mathrm{~mL} / \mathrm{hr}$ (reagent phase) and the average size was reduced to about $265 \mu \mathrm{m}$ (Figure 4c1) when using a 32G needle at a pumping rate of $0.15 \mathrm{~mL} / \mathrm{hr}$ (reagent phase).

The SEM images of the porous amine (Figure 4b2) and hydroxyl (Figure 4c2) containing thiol-ene beads showed nearly 33 and $9 \%$ shrinkage in their dimensions compared to the corresponding optical images. As explained earlier, the shrinkage can be attributed to the low rigidity of the crosslinked thiol-ene network, de-swelling due to removal of porogen, and the nature of -ene monomer used. This is again well supported by their low $\mathrm{T}_{\mathrm{g}}$ values ( 7 and 4 ${ }^{\circ} \mathrm{C}$ ) for the amine and the hydroxyl containing beads respectively (Table 1 ). In order to have high $\mathrm{T}_{\mathrm{g}}$ porous thiol-ene beads, we prepared carboxyl containing thiol-ene beads based on the 
formulation (TT+MA)/TTT, in which TTT has a rigid ring structure. As expected, a higher $\mathrm{T}_{\mathrm{g}}$ value (about $40{ }^{\circ} \mathrm{C}$ ) was observed. Furthermore, we have hardly seen any shrinkage in the carboxyl containing beads from the comparison of the SEM (Figure 4d2) and optical microscopy images (Figure 4d1). This illustrates that, by using appropriate -ene and/or thiol monomers having a rigid structure in a thiol-ene formulation, cross-linked beads with Tgs above room temperature can be produced.

The surface morphology of an individual bead shows a porous rough surface structure for most thiol-ene beads, although a smooth surface is observed for the hydroxyl containing porous beads (Figure 4c2). The size of the pores on the surface of the beads ranges from 50 nm to 1-3 micron as observed from SEM images. The specific surface area using BET method could not be determined for the amine containing porous thiol-ene based beads, possibly due to their lower $\mathrm{T}_{\mathrm{g}}$ (below room temperature) and thereby shrinkage of these beads after washing and drying. Also, a very low specific surface area of $0.7 \mathrm{~m}^{2} / \mathrm{g}$ was measured for the hydroxyl containing porous thiol-ene based beads. On the other hand, the carboxylic acid (prepared using TTT that has high rigid ring structure) containing porous beads prepared by the thiol-ene strategy showed a specific surface area of $4.9 \mathrm{~m}^{2} / \mathrm{g}$.

The representative optical and SEM images of the porous functional beads prepared using thiol-yne formulations containing n-butyl acetate as porogen are shown in Figure 5. Monodisperse beads were obtained for both amine $(\sim 280 \mu \mathrm{m})$ and hydroxyl $(\sim 305 \mu \mathrm{m})$ containing beads as shown by the optical images in Figure $5 a 1$ and $5 b 1$. These beads show 13\% shrinkage in their SEM images, which can be attributed to the removal of porogen from the highly cross-linked thiol-yne beads. The Tg values for these amine and hydroxyl containing thiol-yne systems exhibit higher values compared to the thiol-ene system, 38 and $40{ }^{\circ} \mathrm{C}$ respectively. The SEM images (Figure $5 \mathrm{a} 3$ and 5b3) show a detailed surface morphology of the porous beads under high magnification. A closed-packing of 
interconnected microglobules with dimensions varying from $200 \mathrm{~nm}$ to 1 micron are observed. The specific surface area determined by the BET method is 35.6 and $9.3 \mathrm{~m}^{2} / \mathrm{g}$ for the amine and hydroxyl containing porous beads ( $T_{g}$ values above room temperature) respectively.

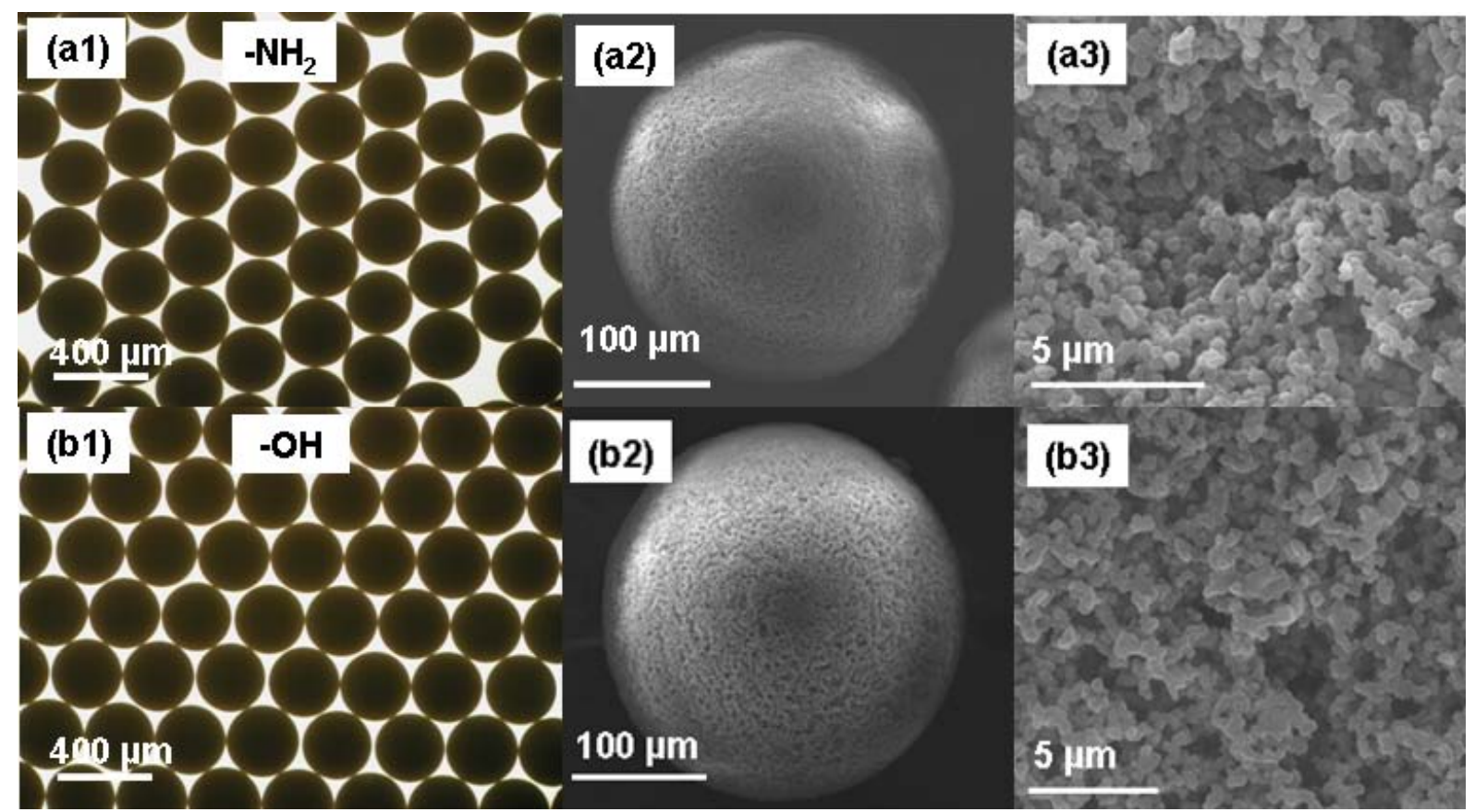

Figure 5: Representative optical and SEM images of the porous functional beads prepared from the 'thiol-yne' formulation of (a) TT/(OY+PA) , (b) TT/(OY+DPPD) .

${ }^{\mathrm{b}} \mathrm{BuAc}$ as porogen

Surprisingly, the specific surface area for the amine containing beads $\mathrm{TT} /(\mathrm{OY}+\mathrm{PA})^{\mathrm{c}}$ based on the porogen xylene was very low, i.e. $3.5 \mathrm{~m}^{2} / \mathrm{g}$. Figure 6 shows representative SEM images

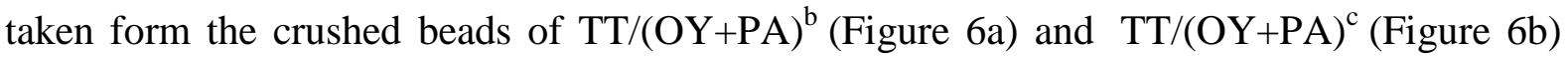
under high magnification. It is clear that the beads based on the porogen BuAc showed well interconnected nanoglobules with micro and mesopores, which in turn showed a high surface area of $35.6 \mathrm{~m}^{2} / \mathrm{g}$. On the other hand, the porous amine beads based on the porogen xylene showed non-porous microglobules with ill-defined interconnections as a result of phase separation, explaining the low porosity of these beads. 


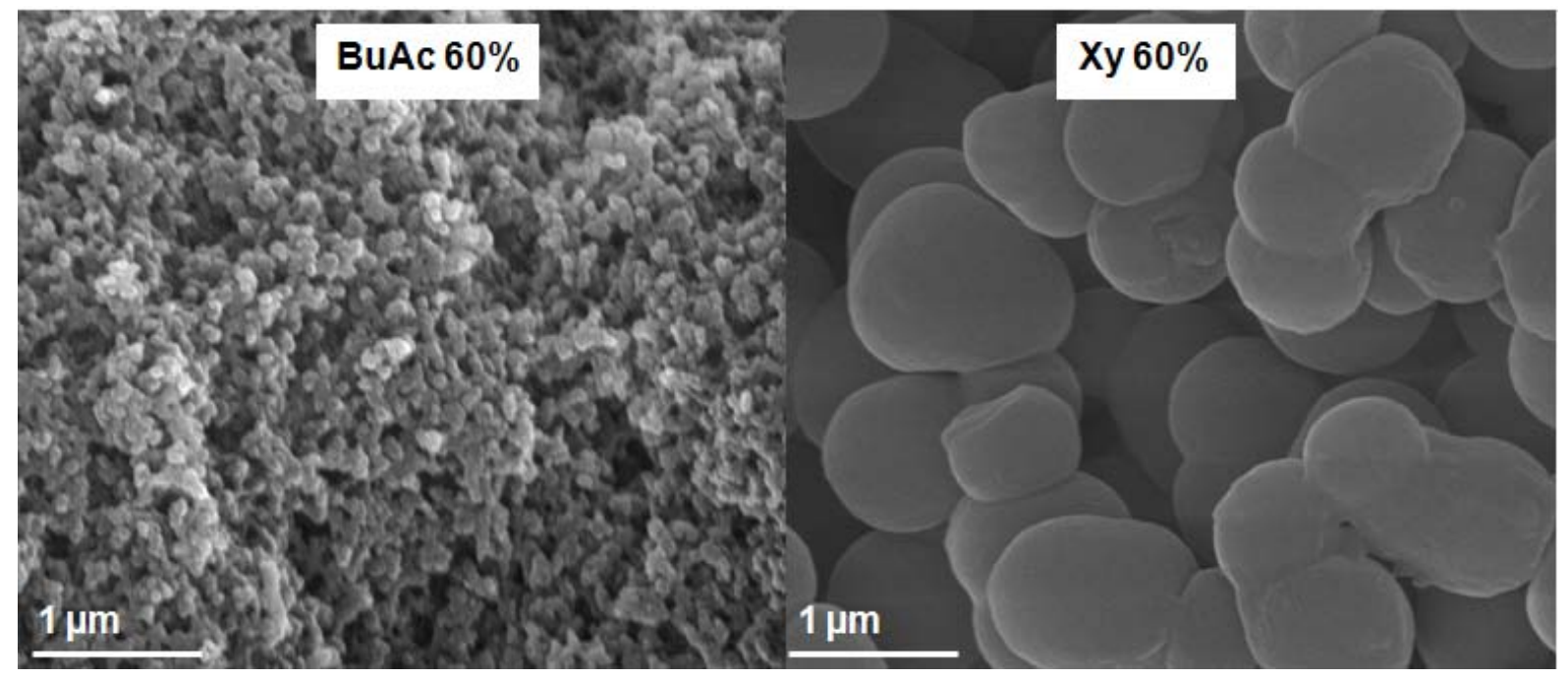

Figure 6: Representative SEM images under high magnification showing interior structure for amine containing porous (a) TT/(OY+PA) ${ }^{b}$ and (b) TT/(OY+PA) ${ }^{c}$.

${ }^{\mathrm{b}} \mathrm{BuAc}$ as porogen, ${ }^{\mathrm{C}} \mathrm{Xy}$ as porogen,

Also, a very low specific surface area of $2.3 \mathrm{~m}^{2} / \mathrm{g}$ was determined for the amine containing porous thiol-yne beads $\left[\mathrm{TT} /(\mathrm{OY}+\mathrm{PA})^{\mathrm{b} \neq}\right]$ that have a $\mathrm{T}_{\mathrm{g}}\left(13^{\circ} \mathrm{C}\right)$ well below room temperature. The low $\mathrm{T}_{\mathrm{g}}$ can be attributed to a reduced crosslink density of the beads owing to the presence of a large amount of monofunctional yne-amine monomer, PA (see Table 1). The effect of porogen on the morphology of beads has been well studied in the literature for free radical copolymerization of vinyl monomers. ${ }^{33,56,57}$ In the former section, it has already been shown that the nature of the porogen is also important for beads derived from thiol-ene formulations (Figure 4). The output is of interest where xylene is used as the sole porogen or mixed with nbutyl acetate (Figure 7) instead of using pure n-butyl acetate for the thiol-yne formulations given in Figure 5. For both of the amine and hydroxyl monomers used, beads exhibited an inner structure composed of globules of almost the same size. As size monodisperse beads provide more reproducible and reliable results for chromatographic applications, commercial columns are packed with such size monodisperse particles ${ }^{58}$. Thiol-yne beads prepared in this study, using xylene as the porogen, are not only size monodisperse but also possess almost monodisperse globules (Figure 7). Such unique size and globule monodisperse beads may 
find chromatographic applications since separation efficiency is directly related with the structure of the column packing. However these beads prepared with $\mathrm{Xy}$ and mixture of solvents $(\mathrm{Xy}+\mathrm{BuAc})$ exhibited reduced values of surface area; 3.5 and $2.2 \mathrm{~m}^{2} / \mathrm{g}$ respectively (Figure 7a and 7b). This is not surprising as it is well known that macroporous beads exhibit lower surface area values compared to micro- and mesoporous beads. ${ }^{59}$ To the best of our knowledge, the highest reported surface area is below $30 \mathrm{~m}^{2} / \mathrm{g}$ for beads produced in a microfluidic setup, ${ }^{33}$ although values over $400 \mathrm{~m}^{2} / \mathrm{g}$ are reported when suspension polymerization is utilized for exactly the same monomers. ${ }^{60}$

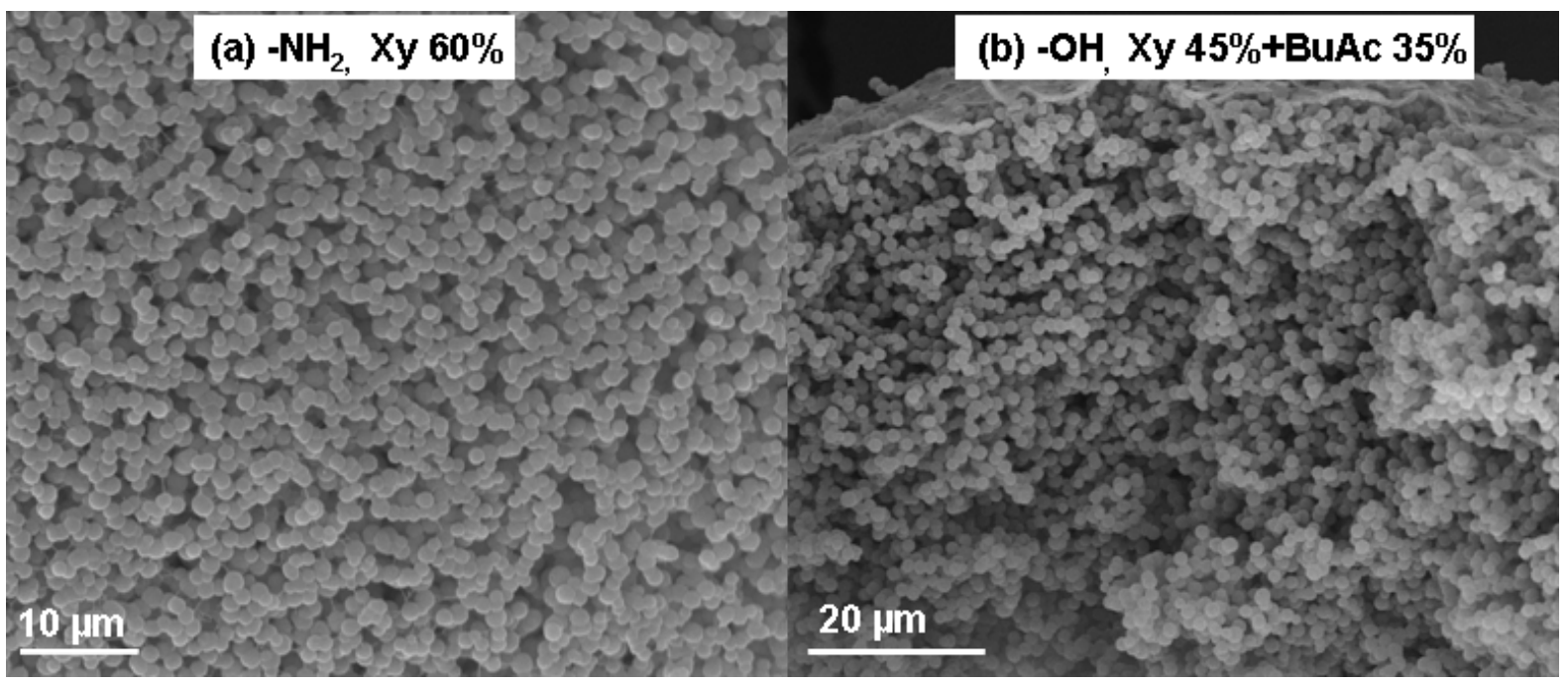

Figure 7: Representative SEM images of the porous functional beads prepared from the 'thiol-yne' formulation of (a) TT/(OY+PA) ${ }^{d}$, (b) TT/(OY+DPPD $)^{e}$.

${ }^{\mathrm{d}} \mathrm{Xy}$ as porogen and ${ }^{\mathrm{e}} \mathrm{Xy}+\mathrm{BuAc}$ as porogen

On the other hand, it has been demonstrated that the rate of the polymerization affects the final porous character of particles in suspension polymerization ${ }^{61}$ Thus, we believe that the fast UV initiated polymerizations may be responsible for the low surface area values for the beads obtained from the microfluidic setup, because this is the only difference between microfluidics and suspension polymerization approaches. 
The yields for porous beads are in the range of 62 to $75 \%$, which is lower when compared to nonporous beads. The possible reason for these lower yields, especially for porous amine containing beads, could be leaching of unreacted monofunctional monomers (e.g. AA and PA) along with porogen during the initial reaction period and/or during curing time into the continuous phase.

\section{Bead functionality}

The presence of functional groups is confirmed by FTIR (Figure 8). A very broad peak around $3450 \mathrm{~cm}^{-1}$ clearly illustrates $-\mathrm{NH}$ and $-\mathrm{OH}$ stretching in the amine (Figure 8a) and hydroxyl (Figure 8c) containing beads. In addition, the strong broad carbonyl stretching absorption at 1780 to $1710 \mathrm{~cm}^{-1}$ indicates the presence of carboxylic acid groups in the carboxyl beads (Figure 8b). The FTIR spectra of the cured beads showed no detectable amount of carbon to carbon allyl or alkyne stretching around 1640 and $2150 \mathrm{~cm}^{-1}$ respectively.

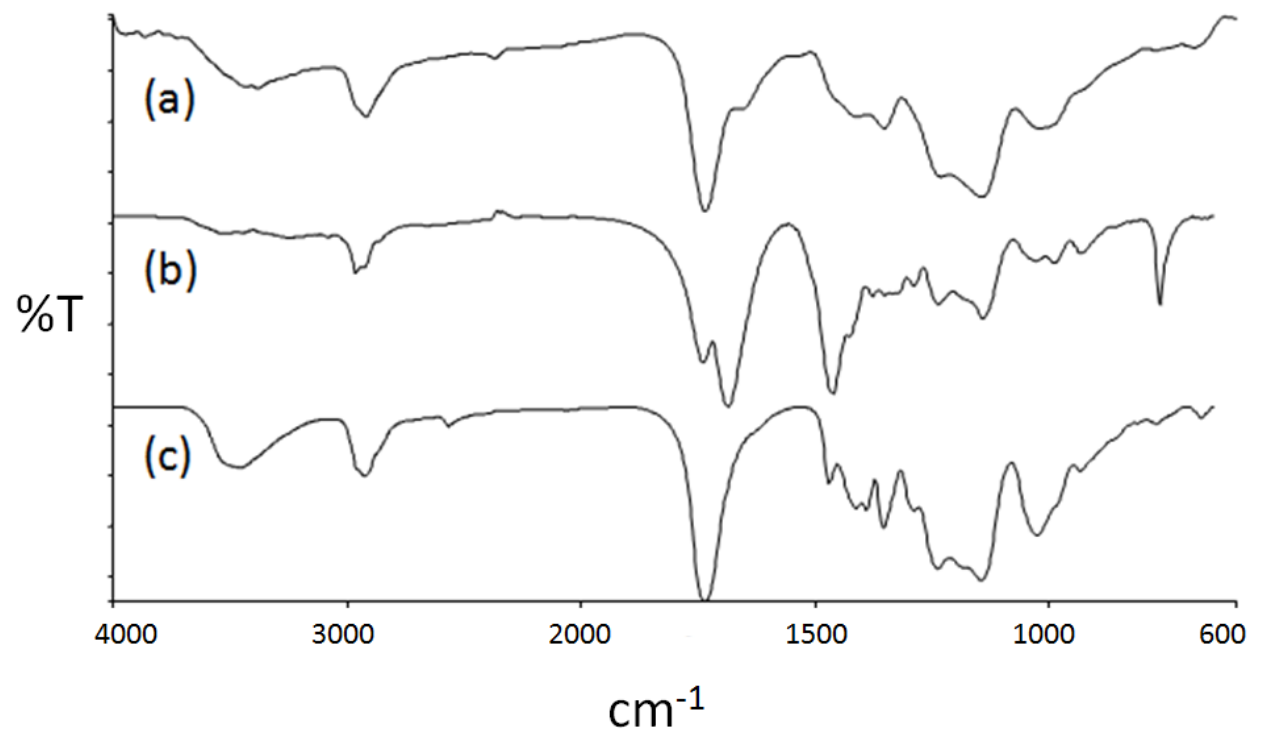

Figure 8. IR spectra for (a) TT/PA, (b) (TT+MA)/TTT ${ }^{b}$, and (c) TT/(OY+DPPD) . ${ }^{b} n-B A$ as Porogen 
Also, Raman spectra (not shown) have not revealed any presence of unreacted groups (thiol or alkene/alkyne) in the beads. This indicates that the conversion of the reactive groups at a 1:1 ratio of thiol to $\pi$-bond is nearly quantitative.

Table 2.Estimation of amine and hydroxyl loading from the respective functionalized beads

\begin{tabular}{|c|c|c|c|c|}
\hline Bead Type & $\begin{array}{l}\text { Sample } \\
\text { Formulation }\end{array}$ & $\begin{array}{l}\text { Ratio of } \\
\text { DAP:AA/ } \\
\text { OY:PA/ } \\
\text { OY:DPPD }\end{array}$ & $\begin{array}{l}\text { Initial } \\
\text { Amine/Hydrox } \\
\text {-yl Loading } \\
\text { (mmol/g) }\end{array}$ & $\begin{array}{l}\text { Amine/Hydroxyl } \\
\text { Loading by Fmoc } \\
\text { Method } \\
(\mathrm{mmol} / \mathrm{g})-(\%)\end{array}$ \\
\hline Nonporous amine * & $\mathrm{TT}(\mathrm{DAP}+\mathrm{AA})$ & 0.65:0.35 & 1.56 & $0.55(35)$ \\
\hline Nonporous hydroxyl * & TT/PTE & - & 1.57 & $0.49(30)$ \\
\hline Nonporous amine $* *$ & TT/PA & - & 3.08 & $0.68(22)$ \\
\hline Nonporous hydroxyl ** & TT/DPPD & & 3.01 & $0.24(8)$ \\
\hline Porous amine * & $\mathrm{TT} /(\mathrm{DAP}+\mathrm{AA})^{\mathrm{a}}$ & 0.65:0.35 & 1.56 & $0.65(42)$ \\
\hline Porous amine * & $\mathrm{TT} /(\mathrm{DAP}+\mathrm{AA})^{\mathrm{b}}$ & $0.65: 0.35$ & 1.45 & $0.69(48)$ \\
\hline Porous hydroxyl * & $\mathrm{TT} / \mathrm{PTE}^{\mathrm{b}}$ & - & 1.59 & $0.68(42)$ \\
\hline Porous amine $* *$ & $\mathrm{TT} /(\mathrm{OY}+\mathrm{PA})^{\mathrm{b}}$ & $0.75: 0.25$ & 0.81 & $0.23(28)$ \\
\hline Porous hydroxyl ** & $\mathrm{TT} /(\mathrm{OY}+\mathrm{DPPD})^{\mathrm{b}}$ & $0.75: 0.25$ & 0.84 & $0.24(29)$ \\
\hline Porous amine $* *$ & $\mathrm{TT} /(\mathrm{OY}+\mathrm{PA})^{\mathrm{b} \neq}$ & $0.25: 1$ & 2.81 & $0.48(17)$ \\
\hline
\end{tabular}

*thiol-ene system; ${ }^{* *}$ thiol-yne system; ${ }^{a}$ DOP as porogen; ${ }^{b}$ n-BA as Porogen, ${ }^{*}$ ratio of thiol to $\pi$-bond is 1:1.25

In Table 2, it is shown that the amine and hydroxyl loading in the porous beads is higher than that of the nonporous beads, which can be explained by the increased accessibility of functional groups due to the porous structure. However, the amine loading for the porous beads $\mathrm{TT} /(\mathrm{OY}+\mathrm{PA})^{\mathrm{b} \neq}$ is lower. This could be attributed to the decreased accessibility of 
amine groups as a result of the high cross-link density and low specific surface area (Table 1). Also, a very low hydroxyl group measurement for the nonporous bead (TT/DPPD) can be explained by its high cross-link density (thiol-yne). In general, the amine and hydroxyl loading determined by the Fmoc method is less than 50\% compared to the initial loading. In general, the lower loading in the beads can be attributed to the restricted access in the highly crosslinked system on one hand and to the leaching of the some fraction of monofunctional monomers to the continuous aqueous phase on the other hand. It is worth to note that the highly sensitive colorimetric thiol test ${ }^{53}$ (with a detection limit as low as $5 \mu \mathrm{mol} / \mathrm{g}$ ) was positive for all the beads, which indicates the presence of unreacted free thiols. We further quantified free thiol groups of various functional beads via the Ellman's colorimetric test. The loading was found to be in the range of 1-7 $\mu \mathrm{mol} / \mathrm{g}$, which is negligible.

\section{Conclusion}

In this work, it has been demonstrated that the rapid radical-mediated 'thio-click' photopolymerizations can be performed in a simple microfluidic setup to produce various macroporous and nonporous monodisperse functional beads without the need of any postfunctionalization steps. For 'thio-click' reactions, the thiol-yne reaction results in an inherently higher cross-link density in the beads, resulting in higher glass transition temperatures compared to the beads produced by the thiol-ene reaction. It is realized that the nature of the porogen used plays an important role on the final porous character. Macroporosity has been proven by SEM images and for some cases low surface areas are obtained, which is expected for macroporous particles. Nevertheless, here we report a maximum value of $35.6 \mathrm{~m}^{2} / \mathrm{g}$, surpassing the results of a previous detailed study. ${ }^{33}$ It is also important that we were able to obtain size and globule monodisperse particles as unique structures via using xylene as the porogen in thiol-yne formulations. Amine, hydroxyl and 
carboxyl groups on the beads have been detected by IR, while Fmoc-glycine is successfully coupled to amino beads proving the capability of these beads to be used as supports for amino acid coupling. This new type of nonporous and macroporous functional resins may find applications in the areas of SPPS, SPOS, scavenging, immobilization and catalysis.

\section{Acknowledgements}

The authors acknowledge Ghent University for offering a 'Special Research Fund' to R.A.P. This work has been financially supported by a Marie Curie Early Stage Research Training Fellowship of the European Community’s Sixth Framework Program under contract number 020643 (M.T.G, Sendichem project) and The Belgian Program on Interuniversity Attraction Poles initiated by the Belgian State, Prime Minister’s office (Program P6/27). 


\section{References}

1. R. Haag and S. Roller, Top. Curr. Chem., 2004, 242, 1-42.

2. I. Bunia, V. Neagu and C. Luca, React. Funct. Polym., 2006, 66, 871-883.

3. N. Miletic, Z. Vukovic, A. Nastasovic and K. Loos, J. Mol. Catal. B: Enzym., 2009, 56, 196-201.

4. N. Fontanals, R. M. Marce, P. A. G. Cormack, D. C. Sherrington and F. Borrull, J. Chromatogr., A, 2008, 1191, 118-124.

5. M. Slater, M. Snauko, F. Svec and J. M. J. Frechet, Anal. Chem., 2006, 78, 4969-4975.

6. W. H. Li and H. D. H. Stover, J. Polym. Sci., Part A: Polym. Chem., 1998, 36, 1543-1551.

7. L. Leeb, P. Gmeiner and S. Löber, QSAR Comb. Sci., 2007, 26, 1145-1150.

8. A. R. Vaino and K. D. Janda, J. Comb. Chem., 2000, 2, 579-596.

9. M. Orzáez, P. Mora, L. Mondragón, E. Pérez-Payá and M. Vicent, Int. J. Pept. Res. Ther., 2007, 13, 281-293.

10. F. Limé and K. Irgum, Macromolecules, 2009, 42, 4436-4442.

11. R. B. Merrifield, J. Am. Chem. Soc., 1963, 85, 2149-2154.

12. D. C. Sherrington, Chem. Commun., 1998, 2275-2286.

13. D. Hudson, J. Comb. Chem., 1999, 1, 333-360.

14. D. Hudson, J. Comb. Chem., 1999, 1, 403-457.

15. http://www.rapp-polymere.com/index m.htm, Accessed 08/01/2010.

16. A. Basso, P. Braiuca, L. De Martin, C. Ebert, L. Gardossi, P. Linda, S. Verdelli and A. Tam, Chem. Eur. J., 2004, 10, 1007-1013.

17. A. Akelah, S. B. Kingston and D. C. Sherrington, Polym. Commun., 1983, 24, 281-284.

18. C. Blackburn, Biopolymers, 1998, 47, 311-351.

19. A. R. Mitchell, S. B. H. Kent, M. Engelhard and R. B. Merrifield, J. Org. Chem., 1978, 43, 28452852.

20. M. Meldal, in Solid-Phase Peptide Synthesis, Editon edn., 1997, vol. 289, pp. 83-104.

21. M. Renil and M. Meldal, Tetrahedron Lett., 1995, 36, 4647-4650.

22. C. C. Zikos and N. G. Ferderigos, Tetrahedron Lett., 1995, 36, 3741-3744.

23. M. Roice, S. F. Christensen and M. Meldal, Chem. Eur. J., 2004, 10, 4407-4415.

24. M. Jean-François and J. M. Lon, Journal of Polymer Science Part A: Polymer Chemistry, 2008, 46, 3182-3192.

25. R. Arshady, Colloid Polym. Sci., 1992, 270, 717-732.

26. M. Antonietti and K. Landfester, Progress in Polymer Science, 2002, 27, 689-757.

27. C. Garcia-Diego and J. Cuellar, Ind. Eng. Chem. Res., 2005, 44, 8237-8247.

28. R. Kita, F. Svec and J. M. J. Frechet, J. Comb. Chem., 2001, 3, 564-571.

29. B. Saracoglu, E. Uguzdogan, C. Golgelioglu and A. Tuncel, Ind. Eng. Chem. Res., 2009, 48, 4844-4851.

30. C. A. Serra and Z. Chang, Chem. Eng. Technol., 2008, 31, 1099-1115.

31. A. S. Utada, L.-Y. Chu, A. Fernandez-Nieves, D. R. Link, C. Holtze and D. A. Weitz, MRS Bull., 2007, 32, 702-708.

32. S. Xu, Z. Nie, M. Seo, P. Lewis, E. Kumacheva, H. A. Stone, P. Garstecki, D. B. Weibel, I. Gitlin and G. M. Whitesides, Angew. Chem., Int. Ed., 2005, 44, 724-728.

33. S. Dubinsky, H. Zhang, Z. Nie, I. Gourevich, D. Voicu, M. Deetz and E. Kumacheva, Macromolecules, 2008, 41, 3555-3561.

34. S. Dubinsky, J. I. Park, I. Gourevich, C. Chan, M. Deetz and E. Kumacheva, Macromolecules, 2009, 42, 1990-1994.

35. G.-R. Yi, S.-J. Jeon, T. Thorsen, V. N. Manoharan, S. R. Quake, D. J. Pine and S.-M. Yang, Synth. Met., 2003, 139, 803-806.

36. A. S. Utada, E. Lorenceau, D. R. Link, P. D. Kaplan, H. A. Stone and D. A. Weitz, Science, 2005, 308, 537-541.

37. Z. Nie, S. Xu, M. Seo, P. C. Lewis and E. Kumacheva, J. Am. Chem. Soc., 2005, 127, 8058-8063. 
38. T. Nisisako, T. Torii, T. Takahashi and Y. Takizawa, Adv. Mater., 2006, 18, 1152-1156.

39. G. A. Gross, C. Hamann, P. M. Günther and J. M. Köhler, Chem. Eng. Technol., 2007, 30, 341346.

40. M. T. Gokmen, W. Van Camp, P. J. Colver, S. A. F. Bon and F. E. Du Prez, Macromolecules, 2009, 42, 9289-9294.

41. A. Gress, A. Volkel and H. Schlaad, Macromolecules, 2007, 40, 7928-7933.

42. K. L. Killops, L. M. Campos and C. J. Hawker, J. Am. Chem. Soc., 2008, 130, 5062-5064.

43. J. W. Chan, B. Yu, C. E. Hoyle and A. B. Lowe, Chem. Commun., 2008, 4959-4961.

44. N. Gupta, B. F. Lin, L. M. Campos, M. D. Dimitriou, S. T. Hikita, N. D. Treat, M. V. Tirrell, D. O. Clegg, E. J. Kramer and C. J. Hawker, Nat. Chem., 2010, 2, 138-145.

45. H. C. Kolb, M. G. Finn and K. B. Sharpless, Angew. Chem., Int. Ed., 2001, 40, 2004-2021.

46. B. D. Fairbanks, T. F. Scott, C. J. Kloxin, K. S. Anseth and C. N. Bowman, Macromolecules, 2009, 42, 211-217.

47. J. W. Chan, C. E. Hoyle and A. B. Lowe, Journal of the American Chemical Society, 2009, 131, 5751-+.

48. M. T. Gokmen, B. G. De Geest, W. E. Hennink and F. E. Du Prez, ACS Appl. Mater. Interfaces, 2009, 1, 1196-1202.

49. E. Quevedo, J. Steinbacher and D. T. McQuade, J. Am. Chem. Soc., 2005, 127, 10498-10499.

50. D. Fournier and F. Du Prez, Macromolecules, 2008, 41, 4622-4630.

51. A. Madder, N. Farcy, N. G. C. Hosten, H. De Muynck, P. J. De Clercq, J. Barry and A. P. Davis, Eur. J. Org. Chem., 1999, 2787-2791.

52. M. Hori, D. J. Gravert, P. Wentworth and K. D. Janda, Bioorg. Med. Chem. Lett., 1998, 8, 2363-2368.

53. J. Caroen and J. Van der Eycken, Tetrahedron Lett., 2009, 50, 41-44.

54. J. P. Badyal, A. M. Cameron, N. R. Cameron, D. M. Coe, R. Cox, B. G. Davis, L. J. Oates, G. Oye and P. G. Steel, Tetrahedron Lett., 2001, 42, 8531-8533.

55. N. B. Cramer, S. K. Reddy, A. K. O'Brien and C. N. Bowman, Macromolecules, 2003, 36, 79647969.

56. D. Horak, Z. Pelzbauer, F. Svec, J. Labsky and M. Bleha, Angew. Makromol. Chem., 1983, 117, 117-129.

57. T. Rohr, S. Knaus, H. Gruber and D. C. Sherrington, Macromolecules, 2002, 35, 97-105.

58. M. J. Benes, D. Horak and F. Svec, J. Sep. Sci., 2005, 28, 1855-1875.

59. H. Zhang, G. C. Hardy, M. J. Rosseinsky and A. I. Cooper, Adv. Mater., 2003, 15, 78-81.

60. D. Horak, F. Svec, M. Bleha and J. Kalal, Angew. Makromol. Chem., 1981, 95, 109-115.

61. F. Svec and J. M. J. Frechet, Macromolecules, 1995, 28, 7580-7582. 
Figure for graphical abstract

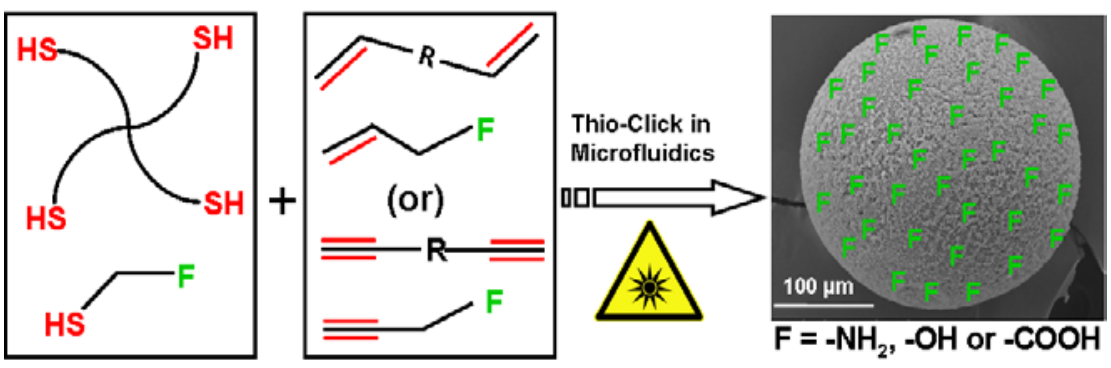

